\title{
Themenschwerpunkt
}

Z Gerontol Geriat 2021 · 54:113-121 https://doi.org/10.1007/s00391-020-01837-9 Received: 16 November 2020

Accepted: 16 December 2020

Published online: 20 January 2021

(c) The Author(s) 2021
Laura C. Blomaard' · Bas de Groot ${ }^{2}$ Jacinta A. Lucke, ${ }^{2,3}$ Jelle de Gelder ${ }^{1,4}$. Anja M. Booijen ${ }^{1,2}$. Jacobijn Gussekloo ${ }^{1,4}$. Simon P. Mooijaart ${ }^{1,5}$

' Department of Internal Medicine, section Geriatrics, Leiden University Medical Center, Leiden, The Netherlands

${ }^{2}$ Department of Emergency Medicine, Leiden University Medical Center, Leiden, The Netherlands ${ }^{3}$ Department of Emergency Medicine, Spaarne Gasthuis, Haarlem, The Netherlands

${ }^{4}$ Department of Public Health and Primary Care, Leiden University Medical Center, Leiden, The Netherlands

${ }^{5}$ Institute of Evidence-Based Medicine in Old Age | IEMO, Leiden, The Netherlands

\section{Implementation of the acutely presenting older patient (APOP) screening program in routine emergency department care}

\section{Supplementary Information}

The online version of this article (https://doi. org/10.1007/s00391-020-01837-9) contains supplementary material, which is available to authorized users.

\section{Introduction}

Older patients form an increasing proportion of emergency department (ED) admissions worldwide and are at higher risk of adverse health outcomes compared to younger patients [1]. The presence of multiple comorbidities, cognitive disorders and atypical disease presentations requires more staff time and resources [2], increases ED length of stay (LOS) and poses organizational challenges $[3,4]$. A comprehensive geriatric assessment (CGA) is an effective method to improve older patients' outcomes [5] but CGA is time-consuming and therefore cannot be routinely applied to every older patient attending the ED. Alternatively, a two-step approach can be used with identification of patients with the highest risk of adverse outcome as a first step, followed by targeted in-

\section{Trial registration}

The Netherlands Trial Register, NTR7171 terventions according to the principles of CGA [6, 7]. To this end, several screening instruments and interventions have been specifically developed for older patients in the ED $[8,9]$ yet few have successfully been disseminated in clinical ED practice.

The acutely presenting older patient (APOP) screening program consists of screening with the APOP screener followed by interventions aimed to improve overall ED care and follow-up of older patients [10]. The program was implemented in routine $\mathrm{ED}$ care in the Leiden University Medical Center (LUMC) together with an education program to enhance awareness amongst nurses and doctors working in the ED. There is extensive evidence that effective implementation of complex interventions can be associated with better outcomes in various settings outside the ED, which implicates that evaluation of implementation is an absolute necessity in program evaluation $[11,12]$. One of the important reasons why screening of older ED patients is rarely carried out in routine care, is the fact that little is known about the practical issues and feasibility of implementation in everyday ED practice [13], although it was recently shown that administra- tion of the APOP screener is feasible in routine ED practice [14].

In the present study we aimed to evaluate the effects of implementation of the APOP screening program in routine ED care by assessing the compliance with interventions in the $\mathrm{ED}$, during hospital admission and after discharge, and the impact on process of care measures, shortly after implementation. We hypothesized that the implementation of the screening program would not negatively influence the usual ED process, for example no prolongation of the ED stay and it would result in improvement of the care for older patients, for example the increase in geriatric assessments.

\section{Methods}

\section{Study design}

This was a prospective study investigating the effects of implementation of the APOP screening program with a beforeafter design, conducted in the ED of the LUMC. The APOP program was kickedoff as part of routine ED care on 1 March 2018. Data were collected during a 2month observation period before implementation ("before") from 4 December 2017 until 2 February 2018, and during 


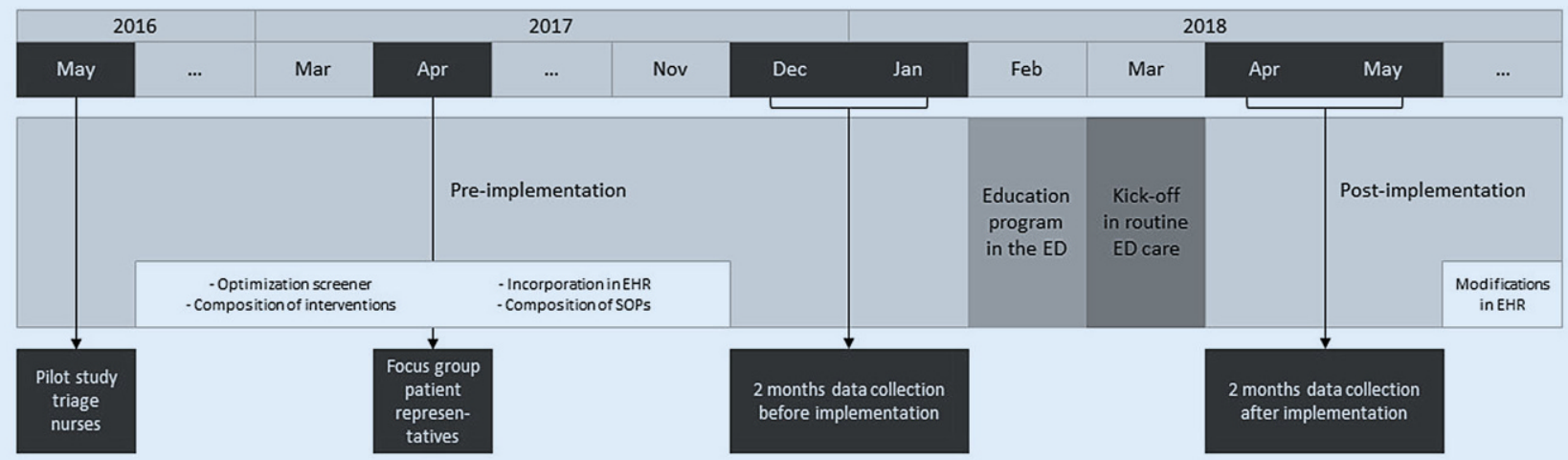

Fig. $1 \Delta$ Overview of the implementation process and data collection periods. Data were collected in multiple periods during the implementation process. In the present study, we evaluated data collected from patients aged $\geq 70$ years visiting the emergency department (ED) during the 2-month observation periods "before" and "after" implementation of the APOP screening program. EHR electronic health record, SOP standard operating procedures

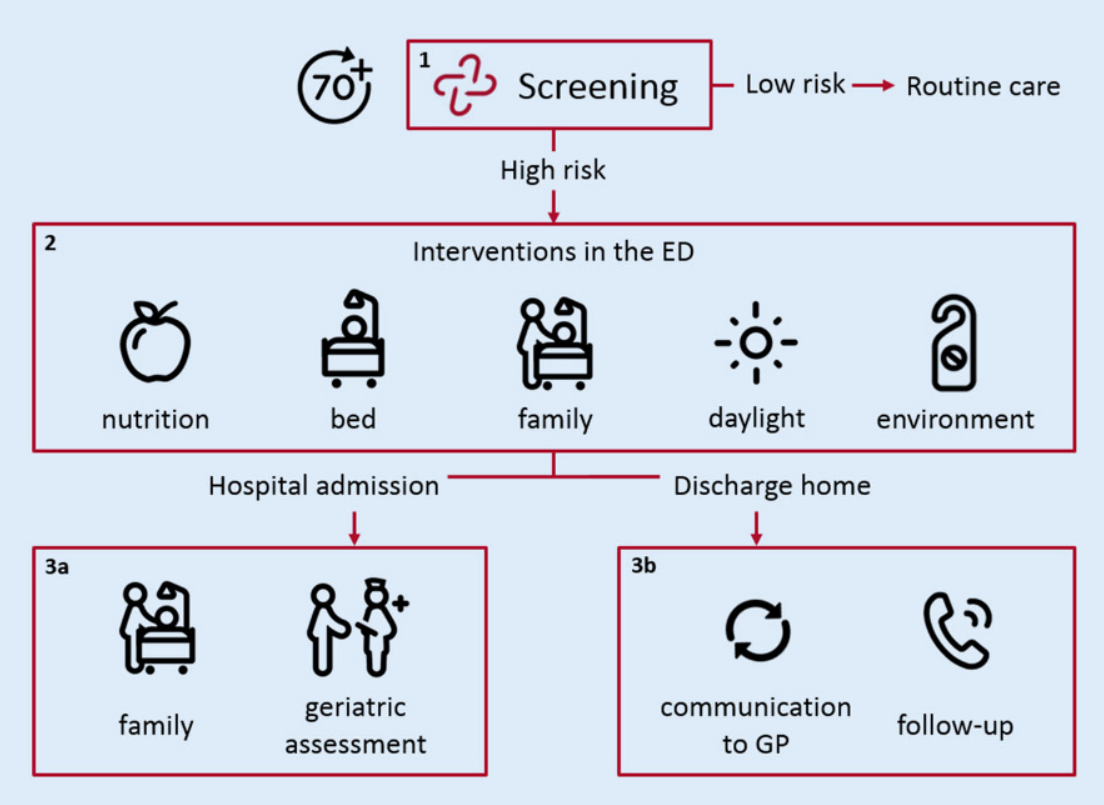

Fig. $2 \Delta$ Overview of the acutely presenting older patient (APOP) screening program. The APOP screening program consists of three parts: firstly, screening older patients for risk of functional decline/mortality and signs of impaired cognition, secondly targeted interventions for high-risk patients in the emergency department (ED) and thirdly interventions for high-risk patients who are hospitalized or discharged home

2 months after implementation ("after") from 2 April 2018 until 3 June 2018. All consecutive patients aged 70 years and older attending the ED during these periods were included in the study. The medical ethics committee of the hospital waived the necessity for formal approval of this study as it closely follows routine care. All patient data were anonymized before analyses were executed. The standards for reporting implementation stud- ies (StaRI) were used to present the study [15].

\section{Context}

The APOP screening program was implemented in the context of an ageing Dutch population where the financial crisis forced governments to stimulate older patients to stay at home longer, while the capacity of home care and nursing homes decreased seriously in the last years. The Netherlands has $\sim 38,000$ hospital beds, $\sim 115,000$ nursing home beds and $\sim 13,000$ general practitioners available for a population of 17 million people. The increased number of older patients presenting to the ED has been a constant debate in politics, and older patients are believed to be the cause of increasing overcrowding of Dutch EDs. This resulted in more attention for older ED patients and an upcoming motivation of ED care providers to improve care for this population.

\section{Setting}

The LUMC is a tertiary care centre with $\sim 26,000$ ED visits per year, of which approximately $20 \%$ are patients aged $\geq 70$ years. In the $\mathrm{ED}$, a triage nurse prioritizes patients based on the disease severity, using the Manchester triage system (MTS) [16]. Patients who bypass ED triage are patients eligible for thrombolytic treatment and patients with an indication for telemetry or cardiac catheterization who are admitted to the emergency cardiac care unit. The ED is staffed each day of the week for $24 \mathrm{~h}$ by ED nurses, ED physicians, ED residents and residents of other specialties. When hospitalization is indicated after ED treatment, most patients are admitted to the acute medical unit (AMU), which is a 24-bed unit for admission up to $48 \mathrm{~h}$ of medical, surgical and selected neurological patients. 
Z Gerontol Geriat 2021·54:113-121 https://doi.org/10.1007/s00391-020-01837-9

(c) The Author(s) 2021

\section{C. Blomaard · B. de Groot · J. A. Lucke · J. de Gelder · A. M. Booijen · J. Gussekloo · S. P. Mooijaart}

\section{Implementation of the acutely presenting older patient (APOP) screening program in routine emergency department care. A before-after study}

\section{Abstract}

Objective. The aim of this study was to evaluate the effects of implementation of the acutely presenting older patient (APOP) screening program for older patients in routine emergency department $(E D)$ care shortly after implementation.

Methods. We conducted an implementation study with before-after design, using the plan-do-study-act (PDSA) model for quality improvement, in the ED of a Dutch academic hospital. All consecutive patients $\geq 70$ years during 2 months before and after implementation were included. The APOP program comprises screening for risk of functional decline, mortality and cognitive impairment, targeted interventions for highrisk patients and education of professionals.
Outcome measures were compliance with interventions and impact on ED process, length of stay (LOS) and hospital admission rate.

Results. Two comparable groups of patients (median age 77 years) were included before $(n=920)$ and after $(n=953)$ implementation. After implementation 560 (59\%) patients were screened of which 190 (34\%) were high-risk patients. Some of the program interventions for high-risk patients in the ED were adhered to, some were not. More hospitalized patients received comprehensive geriatric assessment (CGA) after implementation (21\% before vs. $31 \%$ after; $p=0.002$ ). In $89 \%$ of high-risk patients who were discharged to home, telephone follow-up was initiated.
Implementation did not influence median ED LOS (202 min before vs. $196 \mathrm{~min}$ after; $p=0.152)$ or hospital admission rate $(40 \%$ before vs. $39 \%$ after; $p=0.410$ ).

Conclusion. Implementation of the APOP screening program in routine ED care did not negatively impact the ED process and resulted in an increase of CGA and telephone followup in older patients. Future studies should investigate whether sustainable changes in management and patient outcomes occur after more PDSA cycles.

Keywords

Frail elderly · Geriatric assessment · Geriatric emergency medicine · Implementation science · Quality improvement

\section{Implementierung des Screening-Programms für akut erkrankte ältere Patienten (APOP) in die routinemäßige Versorgung in der Notaufnahme. Eine Vorher-Nachher-Studie}

\section{Zusammenfassung}

Zielsetzung. Beurteilung der Auswirkungen der Implementierung des ScreeningProgramms für ältere Patienten (APOP) in der Routineversorgung der Notaufnahme (ED) kurz nach der Anwendung.

Methoden. Eine Implementierungsstudie mit Vorher-Nachher-Design wurde unter Verwendung des Plan-do-study-act(PDSA)Modells zur Qualitätsverbesserung in der Notaufnahme eines niederländischen akademischen Krankenhauses durchgeführt. Alle konsekutiven Patienten $\geq 70$ Jahre während der 2 Monate vor und nach der Implementierung wurden eingeschlossen. Das APOP-Screening-Programm umfasst eine Untersuchung auf das Risiko von Funktionseinschränkungen, Mortalität und kognitiver Beeinträchtigung, gezielte Interventionen für Hochrisikopatienten und die Schulung von Fachpersonal. Die Ergebnisse wurden anhand der Compliance mit den Interventionen und den Auswirkungen auf die Abläufe in der Notaufnahme, die Verweildauer (LOS) und die Krankenhauseinweisungsrate gemessen. Ergebnisse. Zwei vergleichbare Gruppen von Patienten (mittleres Alter: 77 Jahre) wurden vor $(n=920)$ und nach $(n=953)$ der Implementierung eingeschlossen. Nach der Implementierung wurden 560 (59\%) Patienten gescreent, von denen 190 (34\%) Hochrisikopatienten waren. Die Interventionen für Hochrisikopatienten in der Notaufnahme wurden teilweise eingehalten. Mehr hospitalisierte Patienten erhielten nach der Implementierung ein umfassendes geriatrisches Assessment (CGA; $21 \%$ vorher vs. $31 \%$ nachher; $p=0,002$ ). Bei $89 \%$ der Hochrisikopatienten, die nach Hause entlassen wurden, wurde eine telefonische Nachbetreuung eingeleitet. Die Implementierung hatte keinen Einfluss auf die mediane Verweildauer in der Notaufnahme (202 min vorher vs. 196 min nachher; $p=0,152)$ oder die Krankenhauseinweisungsrate ( $40 \%$ vorher vs. $39 \%$ nachher; $p=0,410$ ).

Schlussfolgerung. Die Implementierung des APOP-Screening-Programms in die routinemäßige Versorgung in der Notaufnahme hatte keine negativen Auswirkungen auf den EDProzess und führte zu einer Zunahme von CGA und telefonischer Nachsorge bei älteren Patienten. In zukünftigen Studien sollte untersucht werden, ob nach weiteren PDSA-Zyklen nachhaltige Veränderungen im Management und in den Patientenergebnissen auftreten.

\section{Schlüsselwörter}

Gebrechliche ältere Menschen · Geriatrische Beurteilung - Geriatrische Notfallmedizin - Implementierungswissenschaft . Qualitätsverbesserung

\section{Implementation strategy}

The implementation strategy was guided by the plan-do-study-act (PDSA) model for quality improvement $[17,18]$. In the preimplementation phase, we used recurring PDSA cycles and assessed barriers and facilitators of the program from pilot studies with ED nurses and focus groups with patient representatives (• Fig. 1). The received input was taken into account during the optimization of the APOP screener [10] and the facilitation of the program in the electronic health records (EHR) and standard operating procedures (SOP). We carried out an education program for ED personnel to enhance awareness during 1 month before the kick-off in routine care. A complete description of the implementation strategy and the education program [19] can be found in appendix 1 . 


\section{Outline of the APOP screening program}

The APOP screening program was developed for $\mathrm{ED}$ patients aged $\geq 70$ years and consists of three parts ( $\bullet$ Fig. 2):

1. Screening. The APOP screener can be administered in $90 \mathrm{~s}$ and identifies the patients' individual risk of 90-day functional decline and/or mortality and signs of impaired cognition in the ED [10]. All patients aged $\geq 70$ years are eligible for screening after routine ED triage. In this study we excluded patients who bypassed triage and patients who were triaged to the immediate urgency level (MTS category "red"), because the APOP screener was not developed and validated for this population. Screening results are saved in the EHR and are visible for all care providers. Patients with a low risk according to screening receive routine care. Patients are at high risk when having a $45 \%$ or higher risk of functional decline and/or mortality within 90 days or when having signs of impaired cognition $[10,14]$.

\section{Interventions for high-risk patients} in the ED. A high risk leads to follow-up actions and interventions. Interventions were based on recommendations from geriatric emergency medicine guidelines $[6,20]$ and were adjusted for use in the Dutch ED setting (appendix 1). The APOP program is a broader program, but in this study we describe the interventions which were evaluated. A full description of these interventions is shown in appendix 2. Physicians and nurses are advised to execute interventions in the ED to increase comfort, family involvement and delirium prevention.

3a Interventions for high-risk patients admitted to the hospital. Interventions can be conducted in an early phase when high-risk patients are hospitalized. Care providers are advised to avoid a prolonged ED LOS and to arrange family involvement during transfer to the ward. The geriatric consulting team is informed automatically by the EHR to arrange a comprehensive geriatric assessment (CGA) during hospital admission.

3b Interventions for high-risk patients discharged home from the ED. The GP is informed about the high-risk result automatically by the EHR in the discharge letter from ED physicians. For highrisk patients who are discharged home from the ED, telephone follow-up is initiated within $24 \mathrm{~h}$ after discharge. The ED nurses contact patients to find out if they have remaining questions about the ED treatment and if they need any help (i.e. clarification of instructions).

\section{Outcomes}

The present study had the following outcome measures: Firstly, compliance with interventions of executed interventions in the ED, during hospital admission or after discharge. Secondly, impact on process of ED care measures: ED LOS and hospital admission rate.

\section{Data collection}

\section{Patient characteristics and organizational factors}

In order to evaluate potential differences between the two data collection periods, we collected patient characteristics and organizational factors before and after implementation. Patient characteristics were collected from the EHR on demographics (age, gender) and severity of disease (Charlson comorbidity index, CCI [21], arrival by ambulance, MTS triage urgency and chief complaint [16] and the specialist first assigned to treat the patient in the ED). To measure organizational factors on a patient level, we used real-time observations in the ED. During the "before" and "after" data collection periods medical students were present in the ED 7 days per week (8.00a.m.-11.00p.m.). Observed organizational factors were: the total number of ED patients at arrival day, the actual number of ED patients at arrival time, the number of occupied AMU beds at arrival time and the national emergency department overcrowding score (NEDOCS) at arrival and departure times [22]. Our hospital uses an adapted, but not yet val- idated, NEDOCS applicable for Dutch EDs (NEDOCS $0-50=$ normal, 51-100 busy, 101-140 overcrowded, 141-180 severe, $>181$ disaster).

1. Screening rate. After implementation, data were collected on the number of patients with executed APOP screening and the results of screening. The number of screened patients divided by the total number of older patients per day yielded the screening rate [14].

\section{Compliance with interventions-in} the ED. The compliance with interventions was measured by absolute numbers of executed interventions in real-time observed older patients "before" and "after" implementation. Additionally, we evaluated the compliance in high-risk patients after implementation. Observations of executed interventions were done from a central place in the ED where most treatment rooms were visible. During the whole ED visit we observed whether older patients: 1) were offered nutrition, 2 ) were placed in a bed instead of a gurney, 3) had family present and 4) were placed in a room with daylight. The stressfulness of the ED environment was measured by the number of involved care providers, the number of treatment room door movements and the proportion of time the treatment room door was open for whole ED LOS. The ED personnel were not informed about the reason for observation.

3a Compliance with interventionshospital admission. For older patients hospitalized in our hospital wards, we observed real time the accompaniment by family when leaving the ED. Consultation of the geriatric team for CGA during admission was collected from the EHR. The compliance was quantified by the number of patients who received CGA divided by the total number of hospitalized older patients.

\section{3b Compliance with interventions-} discharge home. The novel interventions communication to GP and telephone follow-up were collected after implementation from the EHR. The compliance of communication to GP 


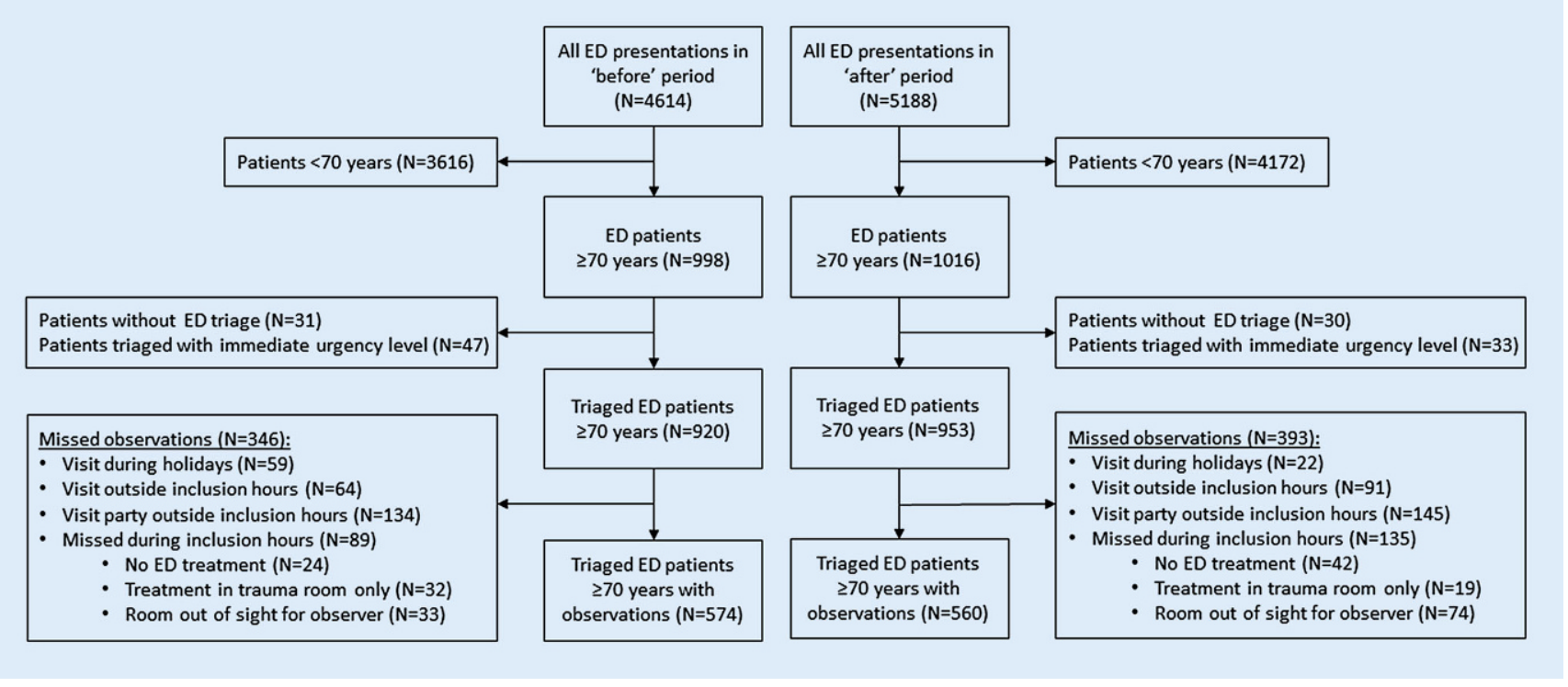

Fig. $3 \triangle$ Flowchart of study population. All consecutive patients aged $\geq 70$ years visiting the emergency department (ED) during the 2-month observation periods "before" and "after" implementation of the APOPscreening program were included, except for patients who bypassed ED triage or patients who were triaged to the immediate urgency level. The screening rate was measured in triaged ED patients $\geq 70$ years in the "after" period. Compliance with interventions was compared in the "before" and "after" period, using real-time observations of ED patients $\geq 70$ years. Process of care measures were compared between all triaged ED patients $\geq 70$ years in the "before" and "after" period

was quantified by the number of highrisk patients with an automatically incorporated discharge letter divided by the total number of high-risk discharged patients. Telephone follow-up compliance was quantified by the number of high-risk patients who received followup divided by the total number of highrisk patients discharged home.

\section{Impact on process of ED care}

Process of care measures were collected from the EHR and were available for all triaged older ED patients before and after implementation. The ED LOS was measured by subtraction of the ED arrival time from the departure time. Hospital admission rate was measured by the number of patients hospitalized from the ED divided by the total number of older ED patients, during the before and after observation period.

\section{Sample size calculation}

The sample size was calculated on ED LOS and hospital admission rate. In a previous analysis of our ED, older patients had a median ED LOS of 189 min (interquartile range, IQR, 125-264 $\mathrm{min}$ ) and the hospital admission rate was $43 \%$ [23]. We considered a change of $15 \mathrm{~min}$ ED LOS and $7 \%$ hospital admission rate as relevant. To detect a difference for the groups before and after with $80 \%$ power and $5 \%$ significance level, per group 891 patients were needed for ED LOS and 796 patients for hospital admission rate.

\section{Statistical analyses}

Continuous data are presented as mean (standard deviation, SD) if normally distributed, and as median (IQR) if skewed. Categorical data are presented as numbers and percentages $(n, \%)$. The following statistical tests were used to assess differences in patient characteristics, organizational factors and compliance with interventions between the after and before period: independent samples t-test for normally distributed data, Mann-Whitney U-test for skewed data and $\chi^{2}$-test for categorical data.

To analyze the impact on process of ED care measures univariable logistic regression was performed, with ED LOS $(<240 \mathrm{~min}, \geq 240 \mathrm{~min})$ and hospital admission (yes, no) as dependent variables and the inclusion period "after" vs. "before" as the independent variable of interest. With multivariable logistic regression we adjusted for age and gender (model 1) and for age, gender and all significantly different variables between the "after" and "before" period (model 2). The results are presented as odds ratios (OR) with $95 \%$ confidence intervals ( $95 \%$ CI). A $p$-value $<0.05$ was determined as statistically significant. Statistical analyses were performed using IBM SPSS Statistics version 25 (IBM Corp., Armonk, NY, USA).

\section{Results}

During the 2-month observation period before implementation ("before") 4614 patients visited the ED of which $920(20 \%)$ were patients aged $\geq 70$ years who were triaged at $\mathrm{ED}$ arrival. In the 2-month observation period after implementation ("after") 953 out of 5188 (18\%) ED patients were triaged patients aged $\geq 70$ years. Of all triaged older patients, 62\% $(N=574)$ was observed "before" and 59\% $(N=560)$ "after" in order to evaluate the compliance with interventions (• Fig. 3). 
Table 1 Patient characteristics and organizational factors before and after implementation

\begin{tabular}{|c|c|c|c|}
\hline & $\begin{array}{l}\text { Before } \\
(N=920)\end{array}$ & $\begin{array}{l}\text { After } \\
(N=953)\end{array}$ & $p$-value \\
\hline \multicolumn{4}{|l|}{ Demographics } \\
\hline Age, years median (IQR) & $77(73-82)$ & $77(73-82)$ & 0.372 \\
\hline Male, $n(\%)$ & $439(47.7)$ & $471(49.4)$ & 0.460 \\
\hline \multicolumn{4}{|l|}{ Severity of disease indicators } \\
\hline Charlson comorbidity index, median (IQR) & $5(4-6)$ & $5(4-7)$ & 0.014 \\
\hline Arrival by ambulance, $n(\%)$ & $316(34.3)$ & $293(30.7)$ & 0.096 \\
\hline Triage urgency, $n(\%)$ & & & 0.585 \\
\hline$>1 \mathrm{~h}$ (green and blue) & $206(22.4)$ & $219(23.0)$ & \\
\hline$<1 \mathrm{~h}$ (yellow) & $449(48.8)$ & $443(46.5)$ & \\
\hline$<15$ min (orange) & $265(28.8)$ & $291(30.5)$ & \\
\hline Chief complaint, $n$ (\%) & & & 0.533 \\
\hline Minor trauma & $256(28.0)$ & $276(29.3)$ & \\
\hline Malaise & $237(25.9)$ & $247(26.2)$ & \\
\hline Dyspnea & $121(13.2)$ & $96(10.2)$ & \\
\hline Abdominal pain & $97(10.6)$ & $91(9.7)$ & \\
\hline Chest pain & $61(6.7)$ & $75(8.0)$ & \\
\hline Loss of consciousness & $44(4.8)$ & $41(4.4)$ & \\
\hline Major trauma & $13(1.4)$ & $15(1.6)$ & \\
\hline Mental health problems & $6(0.7)$ & $10(1.1)$ & \\
\hline Other & $80(8.7)$ & $91(9.7)$ & \\
\hline First assigned specialist in ED, $n$ (\%) & & & $<0.001$ \\
\hline ED physician & $400(44.3)$ & $381(42.1)$ & \\
\hline Internal medicine & $147(16.3)$ & $82(9.1)$ & \\
\hline Neurology & $104(11.5)$ & $104(11.5)$ & \\
\hline Surgery & $63(7.0)$ & $54(6.0)$ & \\
\hline Cardiology & $59(6.5)$ & $71(7.8)$ & \\
\hline Other & $129(14.3)$ & $214(23.6)$ & \\
\hline \multicolumn{4}{|l|}{ Observed organizational factors on patient level } \\
\hline Total number of ED patients on arrival day, mean (SD) & $77(10)$ & $83(12)$ & $<0.001$ \\
\hline Number of ED patients at time of arrival, mean (SD) & $13(5)$ & $13(5)$ & 0.170 \\
\hline Number of occupied AMU beds at time of arrival, mean (SD) & $18(4)$ & $17(4)$ & 0.002 \\
\hline NEDOCS at time of starting medical treatment, median (IQR) & $50(27-70)$ & $51(28-68)$ & 0.998 \\
\hline NEDOCS at time of departure from ED, median (IQR) & $62(42-80)$ & $57(38-72)$ & 0.001 \\
\hline \multicolumn{4}{|c|}{$\begin{array}{l}\text { Demographics and severity of disease indicators were collected from electronic health records. Organi- } \\
\text { zational factors were collected by real-time observations during the ED visit } \\
\text { Missing data } \\
\text { Before: } 36 \mathrm{CCl}, 5 \text { chief complaint, } 18 \text { first assigned specialist, } 4 \text { number of ED patients at time of arrival, } \\
4 \text { number of occupied AMU beds, } 56 \text { NEDOCS at time of start treatment, } 57 \text { NEDOCS at time of depar- } \\
\text { ture } \\
\text { After: } 56 \mathrm{CCl}, 11 \text { chief complaint, } 47 \text { first assigned specialist, } 1 \text { number of ED patients at time of arrival, } \\
2 \text { number of occupied AMU beds, } 75 \text { NEDOCS at time of start treatment, } 38 \text { NEDOCS at time of depar- } \\
\text { ture } \\
N \text { number, IQR interquartile range, SD standard deviation, } A M U \text { acute medical unit, NEDOCS national } \\
\text { emergency department overcrowding score, ED emergency department }\end{array}$} \\
\hline
\end{tabular}

\section{Patient characteristics and organizational factors}

- Table 1 shows the characteristics and organizational factors on a patient level "before" and "after". The median age of patients was the same in both periods:
77 years (IQR 73-82 years). Severity of disease indicators were comparable "before" and "after". Organizational factors "before" and "after" differed: the mean total number of ED patients per day was higher in the "after" period (77 patients (SD 10) before vs. 83 patients (SD 12) af- ter; $p<0.001$ ), but the median NEDOCS at time of ED departure was lower "after" (62 (IQR 42-80) before vs. 57 (IQR $38-72)$ after; $p=0.001)$.

1. Screening rate. During the 2-month observation period "after" implementation 560 (59\%) of the 953 older patients were screened [14]. As a result of screening, 190 (34\%) patients were classified as having a high risk, which made them eligible for interventions.

\section{Compliance with interventions-in} the ED. Compliance with interventions was evaluated by comparison of executed interventions between all realtime observed older patients "before" and "after" (•Table 2). In the "after" period older patients more often received nutrition in the ED (7\% before vs. $12 \%$ after; $p=0.004)$. No improvements were found in nursing on a bed (35\% before vs. $27 \%$ after; $p=0.004$ ), family presence ( $89 \%$ before vs. $84 \%$ after; $p=0.043$ ) and room with daylight (30\% before vs. $34 \%$ after; $p=0.235$ ). Proxies for stressfulness of the ED environment were better "after" for median number of door movements (40, IQR 24-62 before vs. 25, IQR 15-40 after; $p<0.001)$ and median number of involved staff (7, IQR 5-10 before vs. 5, IQR 4-7 after; $p<0.001)$.

3a. Compliance with interventionshospital admission. In total $362(40 \%)$ patients "before" and 368 (39\%) patients "after" were admitted to the hospital. More hospitalized patients received CGA during admission "after" compared to "before" ( $21 \%$ before vs. $31 \%$ after; $p=0.002$ ). Of a total of 92 admitted high-risk patients after implementation $65(71 \%)$ patients received CGA.

\section{3b. Compliance with interventions-} discharge home. After implementation 80 high risk patients were discharged home. In 57 (71\%) patients, the highrisk result was communicated to the GP. Telephone follow-up was initiated in 70 $(89 \%)$ patients. In total $81 \%$ of patients were reached by telephone, of whom $37 \%$ required clarification of home care instructions. 
Table 2 Compliance with interventions before vs. after implementation and compliance with interventions for high-risk screened patients after implementation

\begin{tabular}{|c|c|c|c|c|c|c|c|}
\hline & \multicolumn{4}{|c|}{ Total group of observed older patients } & \multirow{3}{*}{$p$-value } & \multirow{2}{*}{\multicolumn{2}{|c|}{$\begin{array}{l}\text { High-risk screened ob- } \\
\text { served patients } \\
\text { After }\end{array}$}} \\
\hline & \multicolumn{2}{|l|}{ Before } & \multicolumn{2}{|l|}{ After } & & & \\
\hline & $\begin{array}{l}\text { Number } \\
\text { observed }\end{array}$ & Compliance & $\begin{array}{l}\text { Number } \\
\text { observed }\end{array}$ & Compliance & & $\begin{array}{l}\text { Number } \\
\text { observed }\end{array}$ & Compliance \\
\hline \multicolumn{8}{|l|}{ Interventions in the ED } \\
\hline Received nutrition, $n$ (\%) & 540 & $37(6.9)$ & 528 & $63(11.9)$ & 0.004 & 111 & $27(24.3)$ \\
\hline Nursed on bed, $n(\%)$ & 542 & $190(35.1)$ & 534 & $144(27.0)$ & 0.004 & 114 & $42(36.8)$ \\
\hline Family present, $n(\%)$ & 536 & $475(88.6)$ & 518 & $437(84.4)$ & 0.043 & 113 & $98(86.7)$ \\
\hline Room with daylight, $n$ (\%) & 523 & $158(30.2)$ & 508 & $171(33.7)$ & 0.235 & 108 & $44(40.7)$ \\
\hline Number of door movements, median (IQR) & 523 & $40(24-62)$ & 513 & $25(15-40)$ & $<0.001$ & 111 & $31(17-46)$ \\
\hline Number of staff involved, median (IQR) & 524 & $7(5-10)$ & 513 & $5(4-7)$ & $<0.001$ & 111 & $6(4-8)$ \\
\hline Proportion open door time $(\%)^{\mathrm{a}}$, median (IQR) & 423 & $15(5-31)$ & 508 & $16(6-33)$ & 0.190 & 110 & $22(7-38)$ \\
\hline \multicolumn{8}{|l|}{ Interventions at hospital admission ${ }^{\mathrm{b}}$} \\
\hline Family present during admission, $n(\%)$ & 216 & $174(80.6)$ & 174 & $147(84.5)$ & 0.312 & 46 & $37(80.4)$ \\
\hline Geriatric assessment, $n(\%)$ & 343 & $72(21.0)$ & 365 & $114(31.2)$ & 0.002 & 91 & $65(71.4)$ \\
\hline \multicolumn{8}{|l|}{ Interventions at discharge home $e^{c}$} \\
\hline Communication to GP, $n(\%)$ & NA & NA & NA & NA & NA & 80 & $57(71.3)$ \\
\hline Telephone follow-up, $n$ (\%) & NA & NA & NA & NA & NA & 79 & $70(88.6)$ \\
\hline \multicolumn{8}{|c|}{$\begin{array}{l}\text { Total number of triaged patients } \geq 70 \text { years before } N=920 \text {; after } N=953 \text {. Patients were observed real-time when visiting the ED between } 8 \text { a.m. and } 11 \text { p.m. } \\
\text { Total number of observed triaged patients } \geq 70 \text { years before } N=574 \text {; after } N=560 \text {. Total number of high-risk screened patients after implementation } N=190 \\
N \text { number, IQR interquartile range, } N A \text { not applicable, } G P \text { general practitioner, } E D \text { emergency department } \\
\text { a Proportion of time the treatment room door was open for whole ED length of stay in percentage } \\
\text { bNumbers of admitted patients in our hospital: before } N=362 \text {, after } N=368 \text {, high-risk screened patients } N=92 \\
\text { cNumbers of patients discharged home: before } N=467 \text {, after } N=488 \text {, high-risk screened patients } N=80\end{array}$} \\
\hline
\end{tabular}

Table 3 Process of ED care outcomes for patients before and after implementation

\begin{tabular}{llll} 
& $\begin{array}{l}\text { Before } \\
(\mathbf{N = 9 2 0 )}\end{array}$ & $\begin{array}{l}\text { After } \\
(\mathbf{N = 9 5 3 )}\end{array}$ & $\boldsymbol{p}$-value \\
\hline ED LOS (min), median (IQR) & $202(133-290)$ & $196(133-265)$ & 0.152 \\
\hline Hospital admission after ED visit, $n(\%)$ & $362(40.0)$ & $368(38.9)$ & 0.642
\end{tabular}

Missing data

Before: 2 ED LOS, 15 disposition after ED visit. After: 2 ED LOS, 8 disposition after ED visit

$N$ number, IQR interquartile range, $L O S$ length of stay, $E D$ emergency department

\section{Impact on process of ED care}

In - Table 3 , process of ED care outcomes are compared for all included patients "before" and "after". The median ED LOS was comparable between both groups with $202 \mathrm{~min}$ (IQR 133-290min) before vs. $196 \mathrm{~min}$ (IQR 133-265min) after; $p=0.152$. No prolonged ED LOS in the "after" period was found, after adjusting for possible confounders (OR 0.88, 95\%CI 0.66-1.17, $p=0.371$ ) (supplemental - Table 1). Hospital admission rates were comparable between both groups: 362 (40\%) patients before vs. 368 (39\%) patients after; $p=0.642$. After adjustment for possible confounders, the hospital admission rate in the "after" period was lower (OR 0.68, 95\%CI 0.50-0.92, $p=0.013)$.

\section{Discussion}

In this study, the first effects of implementation of the APOP screening program in routine $\mathrm{ED}$ care were evaluated after 1 month by assessing the compliance with interventions and the impact on process of care measures. Interventions for high-risk patients in the ED were partly adhered to. Implementation of the program resulted in increased numbers of executed CGAs during hospitalization, communication of screening results to the GP and telephone follow-up after ED discharge. Implementation had no major effects on ED LOS and hospital admission.

To the best of our knowledge this is the first study evaluating the implementation of a multicomponent screening program for older patients comprising screening and targeted interventions in routine ED care. In a recent substudy we showed that implementation of the APOP screener was feasible with a screening rate of $59 \%$ [14]. Compared to other studies $[13,24,25]$ our screening rate assessed shortly after implementation in routine ED care is relatively high. A screening rate of $100 \%$ is difficult to achieve because the time restraints inherent to a busy ED will prevent nurses administering the screener. Since there are only few ED multicomponent studies published [26] we are only able to compare single components. In one study, telephone follow-up for all older ED patients resulted in $97 \%$ successfully contacted patients of which $40 \%$ required clarification of home care instructions [27], comparable to our results in high-risk older patients. The use of a clinical risk pre- 
diction tool to select high-risk patients and target interventions to those patients most likely to benefit, the increased proportion of patients who receive CGA and the improved communication of screening results to the GP have been associated with improved patient outcomes in other settings $[8,9,28]$. Definitive proof of (cost)effectiveness of the APOP screening program on patient outcomes, such as functional decline, should come from future studies, for example by using a multicenter stepped-wedge design [29].

The present study has several important findings for clinical practice. Firstly, implementation of screening in the ED resulted in improved execution of some individual interventions for older patients during their ED stay, i.e. adequate nutrition. However, the intervention "presence of family" did not increase, probably because this was already very high before implementation, i.e. a ceiling effect. The interventions "nursed on bed" and "room with daylight" also did not improve, probably because they were less feasible due to a lack of capacity (in our ED there are few beds and rooms with daylight available). Secondly, program implementation resulted in a significant increase in the number of executed CGAs, which has been shown to be an effective method to improve outcomes [5]. In $71 \%$ of the high-risk patients CGAs were executed during hospitalization. Therefore, although interventions in the $\mathrm{ED}$ are not always executed, screening is a useful first step to ensure that high-risk patients receive optimal care during hospitalization. The same holds for high-risk patients discharged home from the ED, of which 79\% were reached for telephone follow-up. Finally, implementation of our screening program did not lead to prolonged ED LOS or more hospital admissions. After adjustment for the small differences in the before and after group, there even seem to be less hospital admissions after which is important because impact on capacity is relevant to the feasibility and sustainability of the program.

The repetitive use of the PDSA model as a framework for our implementation strategy helped in understanding barriers and facilitators of implementation [14]. Continuation of future PDSA cycles can help to further improve compliance in our ED and can also help others to start implementation of this screening program elsewhere. The results of the present study are therefore the starting point for new evaluation cycles of the program. Until now, we mainly focused our implementation strategy on the ED nurses, the executors of the screening, which also resulted in mainly nurse-led interventions for highrisk patients. In future, we aim to focus more on physicians and use additional education to increase their awareness and promote a more holistic clinical assessment of older ED patients. Moreover, the interventions of our program were based on recommendations from international guidelines and quality indicators $[6,20]$ and could be updated according to recent recommendations [30]. If other EDs would like to implement a screening program for older patients they can learn from our limitations and adjust their expectations accordingly, i.e. ensure the presence of rooms with daylight and focus on adequate nutrition during an $\mathrm{ED}$ stay.

Our study has several strengths. Firstly, to the best of our knowledge this is the first implementation study evaluating screening and interventions for older patients in routine $\mathrm{ED}$ care on a large scale, using real-time observations. Secondly, our implementation strategy was guided by the generally used PDSA model for quality improvement, resulting in good understanding of barriers and facilitators of implementation. Lastly, the screening program was implemented and evaluated in an unselected population of older ED patients, which is therefore generalizable to other $\mathrm{ED}$ populations.

Our study also has several limitations. Firstly, the before-after study design has time and seasonal variation as a limitation; however, there were no contextual changes between the two data collection periods. Also, we could not detect substantial differences in patient characteristics between the "before" and "after" group. Furthermore, the main outcome measures for the evaluation of the program were process measures-the pro- portion of hospitalized patients with geriatric assessment and the proportion of discharged patients with follow-up telephone calls-which are likely unaffected by time period or seasonal variation. Secondly, before implementation older patients could not be screened. Therefore, we could only compare compliance with interventions on the level of total group ED patients $\geq 70$ years in the before and after periods. Small improvements in compliance with interventions in highrisk patients might therefore have been missed. Finally, the program was implemented in one tertiary care center which limits generalizability.

In conclusion, implementation of the APOP screening program in routine ED care did not negatively impact the ED process and resulted in an increase of CGA and telephone follow-up in older patients. Since this was a first evaluation shortly after implementation, future studies should investigate whether sustainable changes in management and patient outcomes occur after more PDSA cycles.

\section{Corresponding address}

Laura C. Blomaard, MD

Department of Internal Medicine, section Geriatrics, Leiden University Medical Center 9600, 2300 RC Leiden, The Netherlands l.c.blomaard@lumc.nl

Author contributions. $\mathrm{LCB}, \mathrm{BdG}, \mathrm{JAL}, \mathrm{JdG}, \mathrm{AMB}$, $J G$ and SPM: conception and design of the study. SPM: acquiring of funding. LCB: supervision of data collection, data management, statistical analysis and drafting of the manuscript. BdG and SPM: comprehensive monitoring of drafting phase. JAL, JdG, AMB and JG: revising for important intellectual content. All authors gave final approval of the current version of the article.

Funding. This project was supported by ZonMw (project number 627005001 and 6270040011). The Institute for Evidence-Based Medicine in Old Age (IEMO) is funded by the Dutch Ministry of Health, Welfare and Sport and supported by ZonMw (project number 627003001).

\section{Compliance with ethical guidelines}

Conflict of interest. L.C. Blomaard, B. de Groot, J.A. Lucke, J. de Gelder, A.M. Booijen, J. Gussekloo and S.P. Mooijaart declare that they have no competing interests. 
Ethical standards. For this article no studies with human participants or animals were performed by any of the authors. All studies mentioned were in accordance with the ethical standards indicated in each case.

Open Access. This article is licensed under a Creative Commons Attribution 4.0 International License, which permits use, sharing, adaptation, distribution and reproduction in any medium or format, as long as you give appropriate credit to the original author(s) and the source, provide a link to the Creative Commons licence, and indicate if changes were made. The images or other third party material in this article are included in the article's Creative Commons licence, unless indicated otherwise in a credit line to the material. If material is not included in the article's Creative Commons licence and your intended use is not permitted by statutory regulation or exceeds the permitted use, you will need to obtain permission directly from the copyright holder. To view a copy of this licence, visit http://creativecommons.org/licenses/by/4.0/.

\section{References}

1. Aminzadeh F, Dalziel WB (2002) Older adults in the emergency department: a systematic review of patterns of use, adverse outcomes, and effectiveness of interventions. Ann Emerg Med 39(3):238-247

2. Samaras N, Chevalley T, Samaras D, Gold G (2010) Older patients in the emergency department: a review. Ann Emerg Med 56(3):261-269

3. van der Veen D, Remeijer C, Fogteloo AJ, Heringhaus C, de Groot B (2018) Independent determinants of prolonged emergency department length of stay in a tertiary care centre: a prospective cohort study. Scand J Trauma Resusc Emerg Med 26(1):81

4. Ackroyd-Stolarz S, Read Guernsey J, Mackinnon NJ, Kovacs G (2011) The association between a prolonged stay in the emergency department and adverse events in older patients admitted to hospital: a retrospective cohort study. BMJ Qual Saf 20(7):564-569

5. Ellis G, Whitehead MA, O'Neill D, Langhorne $P$, Robinson D (2011) Comprehensive geriatric assessment for older adults admitted to hospital. Cochrane Database Syst Rev. https://doi.org/10. 1002/14651858.CD006211.pub2

6. Rosenberg MS, Carpenter CR, Bromley $M$, Caterino JM, Chun A, Gerson L et al (2014) Geriatric emergency department guidelines. Ann Emerg Med 63(5):e7-e25

7. Ellis G, Marshall T, Ritchie C (2014) Comprehensive geriatric assessment in the emergency department. Clin Interv Aging 9:2033-2043

8. Carpenter CR, Shelton E, Fowler S, Suffoletto $B$ Platts-Mills TF, Rothman RE et al (2015) Risk factors and screening instruments to predict adverse outcomes for undifferentiated older emergency department patients: a systematic review and meta-analysis. Acad Emerg Med 22(1):1-21

9. Karam G, Radden Z, Berall LE, Cheng C, Gruneir A (2015) Efficacy of emergency department-based interventions designed to reduce repeat visits and other adverse outcomes for older patients after discharge: a systematic review. Geriatr Gerontol Int 15(9):1107-1117

10. de Gelder J, Lucke JA, Blomaard LC, Booijen AM, Fogteloo AJ, Anten S et al (2018) Optimization of the APOP screener to predict functional decline or mortality in older emergency department patients: Cross-validation in four prospective cohorts. Exp Gerontol 110:253-259

11. Durlak JA, DuPre EP (2008) Implementation matters: a review of research on the influence of implementation on program outcomes and the factors affecting implementation. Am J Community Psychol 41(3-4):327-350

12. Peters DH, Adam T, Alonge $O$, Agyepong IA, Tran $N$ (2013) Implementation research: what it is and how to do it. BMJ347:f6753

13. Elliott A, Hull L, Conroy SP (2017) Frailty identification in the emergency department-a systematic review focussing on feasibility. Age Ageing 46(3):509-513

14. Blomaard LC, Mooijaart SP, Bolt S, Lucke JA, de Gelder J, Booijen AM et al (2020) Feasibility and acceptability of the "Acutely Presenting Older Patient" screener in routine emergency department care. Age Ageing 49(6):1034-1041

15. Pinnock $H$, Barwick M, Carpenter CR, Eldridge $S$, Grandes G, Griffiths CJ et al (2017) Standards for Reporting Implementation Studies (StaRI) Statement. BMJ356:i6795

16. Mackway-Jones K(1997)Manchester TriageGroup: emergency triage. BMJ Publishing Group, London

17. Speroff T, O'Connor GT (2004) Study designs for PDSA quality improvement research. Qual Manag Health Care 13(1):17-32

18. Taylor MJ, McNicholas C, Nicolay C, Darzi A, Bell D, Reed JE(2014) Systematic review of the application of the plan-do-study-act method to improve quality in healthcare. BMJQual Saf 23(4):290-298

19. Conroy $S$, Nickel $C H$, Jónsdóttir $A B$, Fernandez M, Banerjee J, Mooijaart S et al (2016) The development of a European curriculum in Geriatric Emergency Medicine. Eur Geriatr Med 7(4):315-321

20. McCusker J, Vu MTT, Veillette N, Cossette S, Vadeboncoeur A, Ciampi A et al (2018) Elderfriendly emergency department: development and validation of a quality assessment tool. J Am Geriatr Soc 66(2):394-400

21. Charlson $M E$, Pompei $P$, Ales $K L$, MacKenzie $C R$ (1987) A new method of classifying prognostic comorbidity in longitudinal studies: development and validation. JChronic Dis 40(5):373-383

22. Weiss SJ, Derlet R, Arndahl J, Ernst AA, Richards J, Fernandez-Frackelton Metal (2004) Estimating the degree of emergency department overcrowding in academic medical centers: results of the National ED Overcrowding Study (NEDOCS). Acad Emerg Med 11(1):38-50

23. Hofman SE, Lucke JA, Heim N, de Gelder J, Fogteloo AJ, Heringhaus Cetal (2016) Prediction of 90-day mortality in older patients after discharge from an emergency department: a retrospective follow-up study. BMC Emerg Med 16(1):26

24. Schoenenberger AW, Bieri C, Ozguler O, Moser A, Haberkern M, Zimmermann $\mathrm{H}$ et al (2014) A nove multidimensional geriatric screening tool in the ED: evaluation of feasibility and clinical relevance. Am JEmerg Med 32(6):623-628

25. Asomaning N, Loftus C (2014) Identification of seniors at risk (ISAR) screening tool in the emergency department: implementation using the plan-do-study-act model and validation results. J Emerg Nurs 40(4):357-364.e1

26. Preston L, van Oppen JD, Conroy SP, Ablard S, Buckley Woods H, Mason SM (2020) Improving outcomes for older people in the emergency department: a review of reviews. Emerg Med J 36(12):754-761

27. Jones JS, Young MS, LaFleur RA, Brown MD (1997) Effectiveness of an organized follow-up system for elder patients released from the emergency department. Acad Emerg Med 4(12):1147-1152

28. Hastings SN, Heflin MT (2005) A systematic review of interventions to improve outcomes for elders discharged from the emergency department. Acad Emerg Med 12(10):978-986

29. Ferm L, Rasmussen CDN, Jorgensen MB (2018) Operationalizing a model to quantify implementation of a multi-component intervention in a steppedwedge trial. Implement Sci 13(1):26

30. Schuster S, Singler K, Lim S, Machner M, Döbler K, Dormann H (2020) Quality indicators for a geriatric emergency care (GeriQ-ED) — an evidence-based delphi consensus approach to improve the care of geriatric patients in the emergency department. Scand J Trauma ResuscEmerg Med 28(1):68 